\section{COMMENTS ON THE PAPER "DIFFUSION OF CARBON DIOXIDE WITHIN MOLECULAR SIEVES PAR'TICLES"}

\section{Dear Sir:}

In a recent paper $^{3)}$ Takeuchi and Kawazoe measured breakthrough curves for $\mathrm{CO}_{2}$ in columns packed with Molecular Sieves 4A, 5A and 13X, respectively. In modelling their results they found good agreement for the $5 \mathrm{~A}$ and $13 \mathrm{X}$ columns with their Eq. (14)

$$
C / C_{0}=\frac{1}{2}(1+\operatorname{erf} E)
$$

which is the same as the asymptotic solution of Rosen $^{2}$. For the 4A column, however, it was necessary for them to use their Eq. (13), which is an analytical solution containing an infinite integral. We will not consider their use of the Babcock approximation, Eq. (25) in Lit. 3). The authors state that the ratio of column height to velocity, $Z / u$, was too low in the $4 \mathrm{~A}$ column to permit use of the erf-equation. It may be shown that the $Z / u$-ratio is not a sufficient criterion. We have derived a solution for calculating breakthrough curves with linear isotherms using the Hermite polynomials with coefficients which are functions of the statistical moments ${ }^{1)}$. We show that Eq. (14) above is derived by truncating the series at the term including the second statistical moment. We also show that this equation deviates by about $1 \%$ from the more exact solution for values of a parameter $\eta<0.01$ and by about $5 \%$ for $\eta<0.1$. At $\eta>0.1$ the accuracy of the erf-solution deteriorates rapidly. On the basis of the nomenclature in (1), the parameter is defined as

$$
\eta=\stackrel{u}{K_{F} a_{v} \cdot Z}
$$

Using the data in (1) we calculate for the series of measurements with $5 \mathrm{~A}, 0.005<\eta<0.04$; with $13 \mathrm{X}$, $0.01<\eta<0.06$ and with $4 \mathrm{~A}, 0.11<\eta<0.4$.

Thus it may be seen that the experience of Takeuchi and Kawazoe in using the erf-Equation substantiates our parametric calculations in Literature 1).

\section{Literature Cited}

1) Radeke, K.-H., K. Wiedemann and D. Gelbin.: Chem.
Tech., 28, 476 (1976).

2) Rosen, J. B.: Ind. Eng. Chem., 46, 1590 (1954).

3) Takeuchi, Y. and K. Kawazoe: J. Chem. Eng. Japan, 9, 46 (1976).

D. GELBIN AND K.-H. RADEKE Zentralinstitut für physikalische Chemie der AdW der DDR, 1199 Berlin, Rudower Chaussee 5

(Received Oct. 2, 1976.)

\section{Dear Sir:}

The letter from Dr. Gelbin and Dr. Radeke forwarded to the editor regarding our paper ${ }^{3)}$ seems to be acceptable. Their criticism of our paper based on their study ${ }^{23}$ will be instructive to general readers, too.

We do not dispute the letter from Dr. Gelbin and Dr. Radeke, however we would like to explain briefly the followings to avoid any misunderstanding which may arise on general readers' part, if nothing is mentioned.

We wrote "As $Z / u$ was too short to use Eq. (14), an exact solution, Eq. (13) was used to analyze the breakthrough curves for MS 4A system", simply because the operational conditions we could choose were only $Z$ and $u$, and $K_{F} a_{v}$ was not known beforehand.

Furthermore, since we had already known an exact solution $^{2)}$, we did not carry out experiments on the conditions to fit Eq. (14).

\section{Nomenclature}

$K_{F} a_{v}=$ overall mass transfer coefficient $\quad\left[\mathrm{sec}^{-1}\right]$

$u \quad=$ linear flow rate $\quad[\mathrm{cm} / \mathrm{sec}]$

$Z \quad=$ bed length $\quad[\mathrm{cm}]$

\section{Literature Cited}

1) Kawazoe, K. and Y. Takeuchi: J. Chem. Eng. Japan, 7, 431 (1974).

2) Radeke, K-H, K. Wiedemann and D. Gelbin: Chem. Tech., 28, 476 (1976).

3) Takeuchi, Y. and K. Kawazoe: J. Chem. Eng. Japan, 9, 46 (1976)

YASUSHI TAKEUCHI

Meiji University, Kawasaki 214

Kunitaro KAWAZOE

University of Tokyo, Tokyo 106

(Received Nov. 13, 1976.) 